\title{
Fire safety of ETICS with wood fibreboards for multi-storey buildings - first research and development results
}

\author{
Judith Küppers ${ }^{1}$, Jochen Zehfuß ${ }^{1}$, Felix Steeger ${ }^{2}$ and Björn Kampmeier ${ }^{2}$ \\ ${ }^{1}$ Technische Universität Braunschweig, Institute of Building Materials, Concrete Construction and Fire \\ Protection (iBMB), Braunschweig, Germany \\ ${ }^{2}$ Hochschule Magdeburg-Stendal (HSMD), Division of Fire Safety and Structural Design, Magdeburg, \\ Germany
}

\begin{abstract}
Wood fibreboards can serve as alternative sustainable insulation material for external thermal insulation component systems (ETICS). In Germany, the application of ETICS with wood fibreboards is restricted to low buildings. The restrictions are mainly caused by the smouldering tendency of the wood fibreboards. Thus, the development of an ETICS with wood fibreboards for multi-storey buildings complying with the requirements would provide a new scope of application for this sustainable insulation material.

This paper presents first results of standardised and innovative investigation methods as basis for the development. These investigations and analyses concern the fire behaviour, especially smouldering processes, the plaster system, other constructive protection measures as well as risk and safety analyses.
\end{abstract}

\section{INTRODUCTION}

External thermal insulation component systems (ETICS) serve as outside insulation of exterior walls. For many constructions, they are indispensable under the applicable increased requirements for thermal protection and energy efficiency of buildings in Germany. This applies not only to new buildings, but in particular to existing buildings.

In addition to energy efficiency, there are fire protection requirements valid for the construction of facades. The model building code of Germany (representative of the state building codes) generally divides buildings by their height and utilization units' area into five building-classes (Table 1). For building-class 1 to 3, e.g. single family houses, building materials with normal flammability are allowed. In building-class 4 and 5, e.g. multi-storey apartment buildings, the requirements for combustible insulation materials of ETICS are higher (low flammability). Within the European classification system the C-class represents the minimum requirements valid for low flammability according to the German model building code and the Building Rules List. It has also to be considered that for sustainable materials like wood fibreboards, their smouldering tendency is the main reason why they do not comply with the requirements of the application as ETCIS in higher building-classes.

This is an Open Access article distributed under the terms of the Creative Commons Attribution License 2.0, which permits unrestricted use, distribution, and reproduction in any medium, provided the original work is properly cited. 
Table 1. Building-classes and fire protection requirements for ETICS according to the model building code of Germany.

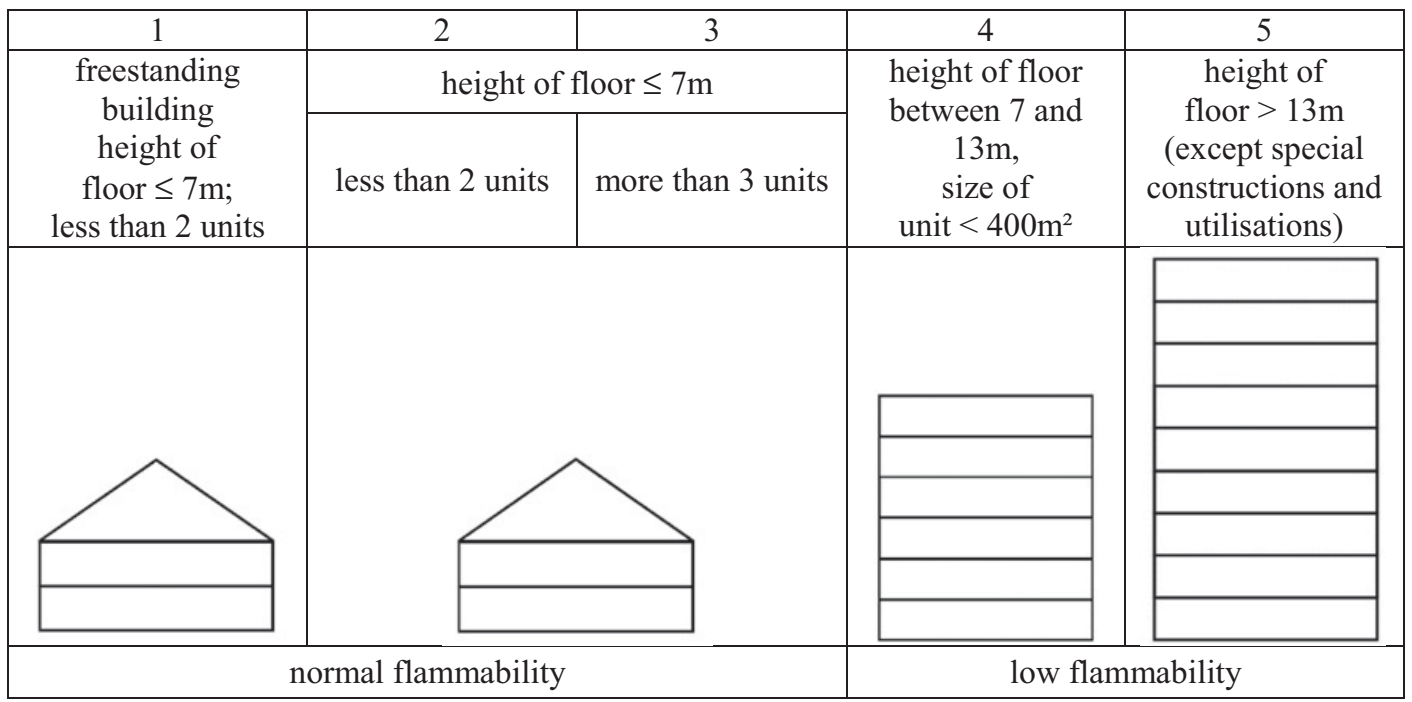

The objective of the presented research project is to improve the wood fibreboards for reducing smouldering or stopping it with barriers at an exactable level, thus developing an ETICS for multistorey buildings complying with the requirements. The German Federal Ministry of Economics and Technology funds this research within the Central Innovation Program for Small- and Medium-sized Enterprises (ZIM). The operating institutions in this research project are the iBMB of the Technische Universität Braunschweig, the University of Applied Sciences in Magdeburg (HSMD), the Fraunhofer Institute for Wood Research (WKI) and industrial partners.

In general, two ways are pursued developing the ETICS: On the one hand, a "thick layer system" is examined, where the plaster systems mainly should protect the combustible materials. On the other hand, the whole system and mainly the wood fibreboards shall be enhanced to reduce fire behaviour and smouldering processes to an acceptable level.

\section{RESEARCH AND DEVELOPMENT RESULTS PROVIDED BY INDUSTRY}

The involved wood fibreboard producers provided information about several fire tests. Small- and medium-size tests like the single-flame source test (ISO 11925-2), "Brandschachttest" (DIN 410215/16) and SBI test (EN 13823) yield information about the fire behavior. They are standardised and provide comparable results. These tests of different (equipped) wood fibreboards are taken into consideration for planning and analysing the tests within this project. In addition, results of three facade tests were provided, which did not yet lead to a system that complies with all requirements, but yield useful results for further development.

\section{FIRE BEHAVIOUR AND SMOULDERING PROCESSES}

As first step of the developing process, the fire behaviour and smouldering processes of the wood fibreboards are studied. In addition to the aforementioned results, literature about smouldering processes, test methods and results, e.g. [1-7], was studied and test series were planned.

The most influencing parameters have to be studied for analysing the fire behaviour and especially smouldering for getting a better understanding of this complex mechanism. Flame-retardants are an 

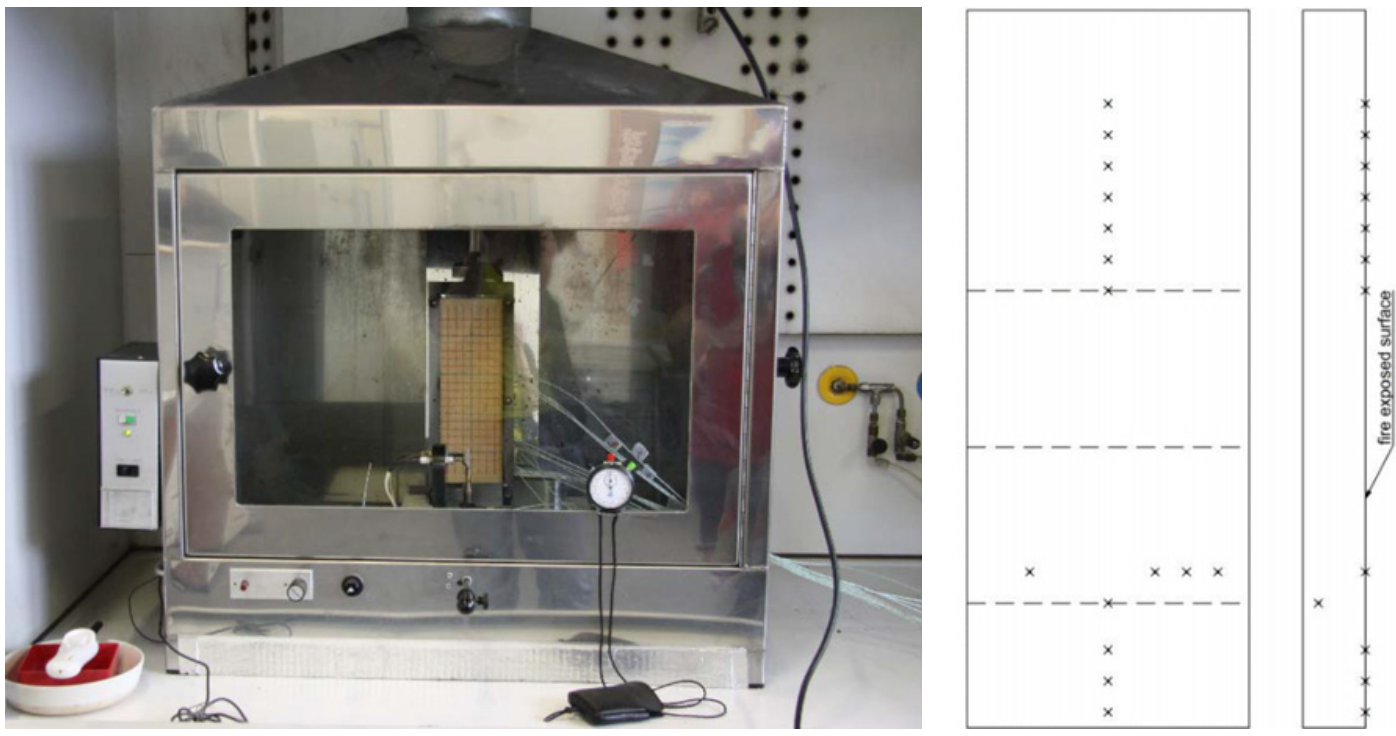

Figure 1. Modified single-flame source test and example of thermocouple placement [iBMB].

important influencing parameter and well known for enhancing wood fibreboards and other sustainable building materials. Another main parameter influencing the smouldering processes is the density of the wooden boards.

In order to investigate the aforementioned and further influencing parameters, different test series are in process. For example, in the cone-calorimeter according to ISO 5660 the ignition temperature, mass loss rate and heat release rate (by oxygen calorimetry) are measured comparing different equipped boards. Samples for cone-calorimeter-tests are small $\left(10 \times 10 \mathrm{~cm}^{2}\right)$ and the smoke gases are analysed. Due to this, these tests are effective for test series with a large amount of samples. On the other hand, the horizontal placement and the full-faced fire exposure of the samples does not correspond with the application and expected fire scenario. Due to this, additional tests are in process.

In addition to the single-flame source tests provided by the project partners, some more tests were performed. The test-procedure was modified for orienting tests with a longer fire exposure and samples equipped with thermocouples (Fig. 1). In these tests, the thermocouples were not only placed upwards. To receive more detailed information, e.g. about the smouldering velocity in different directions (in or against the upward current and lateral propagation) additional, thermocouples were placed. These tests were performed for orientation and specification of further tests.

In European standard fire tests for building materials, performance criteria for smouldering are missing. Thus, in Germany the smouldering of materials is investigated by performing the 'Brandschachttest' according to DIN 4102-15/16. At the European level, with the draft standard prEN 16733 (Fig. 2) smouldering shall be assessed. Both test methods require an equipment of the samples with thermocouples for assessing the measured temperature.

Different equipped boards of $300 \times 800 \mathrm{~mm}^{2}$ are investigated in this test device and analysed. Typical temperature-time curves of the thermocouples placed in the samples are shown in Fig. 3. The results of the modified single-flame source tests (equipped with thermocouples) lie in the same range like the tests according to prEN 16733. It is characteristical that the smouldering process starts with a rapid temperature increase in or close to the initial area (TC 1 and 2), followed by a plateau at around 80 to $110^{\circ} \mathrm{C}$ and an additional, but faster, temperature increase. While smouldering, the first increase is 

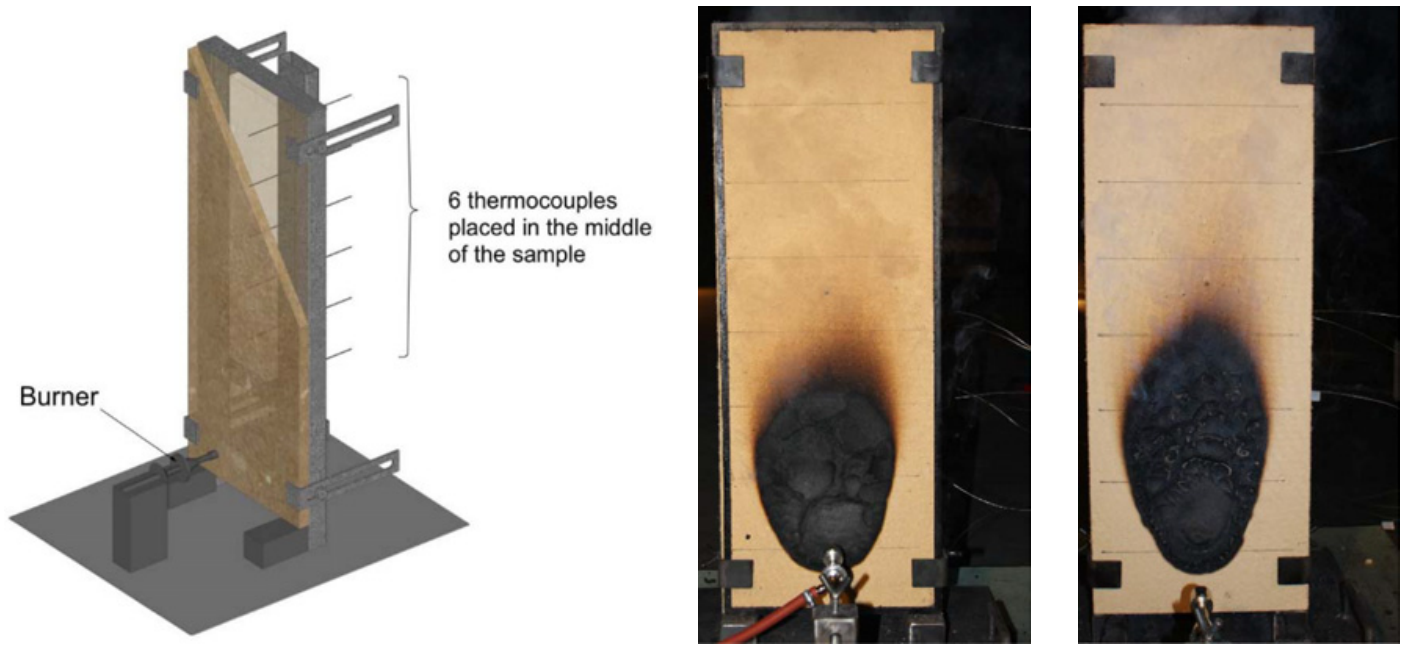

Figure 2. Test device (left) and wood fibreboards with (middle) and without flame-retardants (right) shortly after fire exposure [drawing:iBMB, pictures:HSMD].
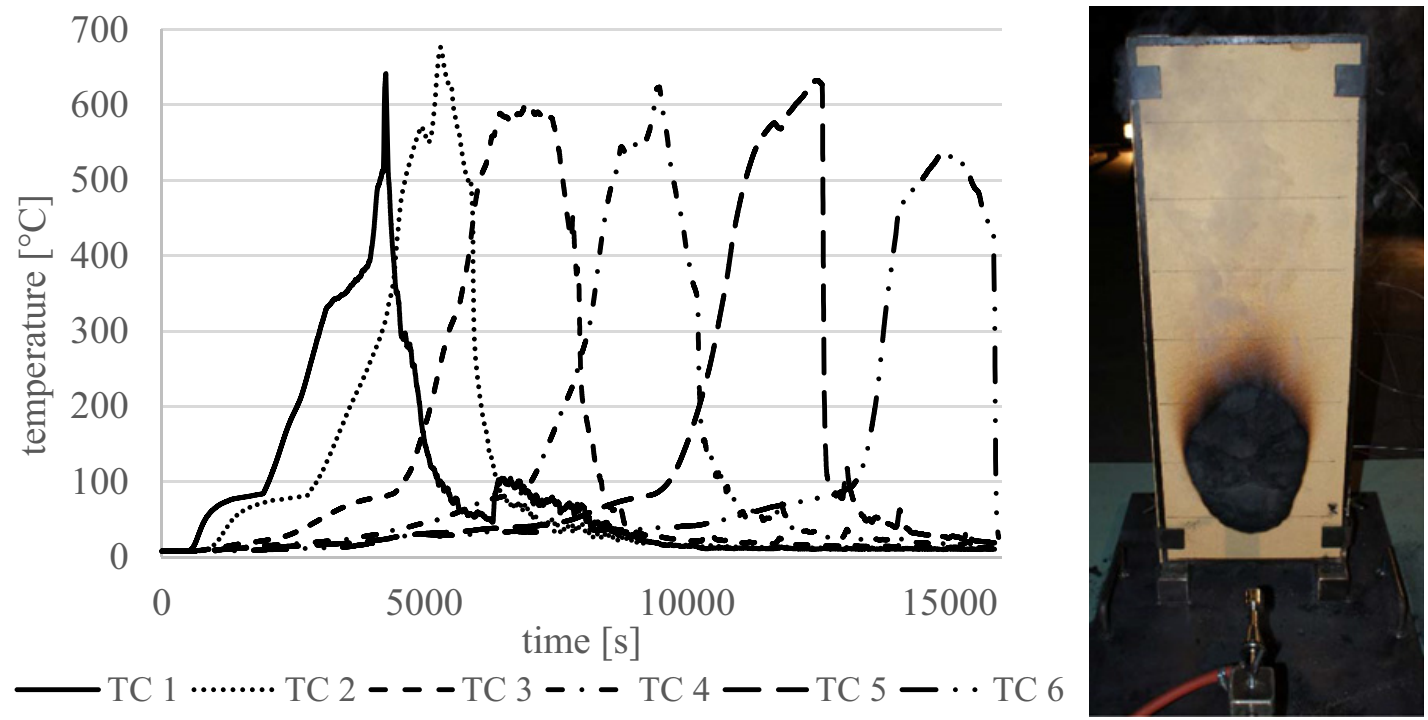

Figure 3. Temperature-time curves of a wood fibreboard with flame-retardants and a density of ca. $180 \mathrm{~kg} / \mathrm{m}^{3}$ tested according to prEN 16733 and picture shorty after fire exposure [HSMD].

slower than in (or close to) the initial area and the inflexion point at around 80 to $110^{\circ} \mathrm{C}$ is followed by a temperature increase nearly as fast as in the initial area.

These test results can be used for determining the smoldering velocity. Therefore only temperatures higher than $110^{\circ} \mathrm{C}$ should be considered. Although, right now only some tests were carried out, first results thick boards are showing the expected influence of the density: The smouldering velocity decreases, when the density increases. In detail, the smoldering velocity was determined, for example, as $0.11 \mathrm{~m} / \mathrm{h}$ up to $0.18 \mathrm{~m} / \mathrm{h}$ for densities of around $130 \mathrm{~kg} / \mathrm{m}^{3}$ up to $190 \mathrm{~kg} / \mathrm{m}^{3}$ by estimating the time difference for temperature steps of $200^{\circ} \mathrm{C}$ to $400^{\circ} \mathrm{C}$ at the two highest thermocouples (TC 5 and 6 ). 

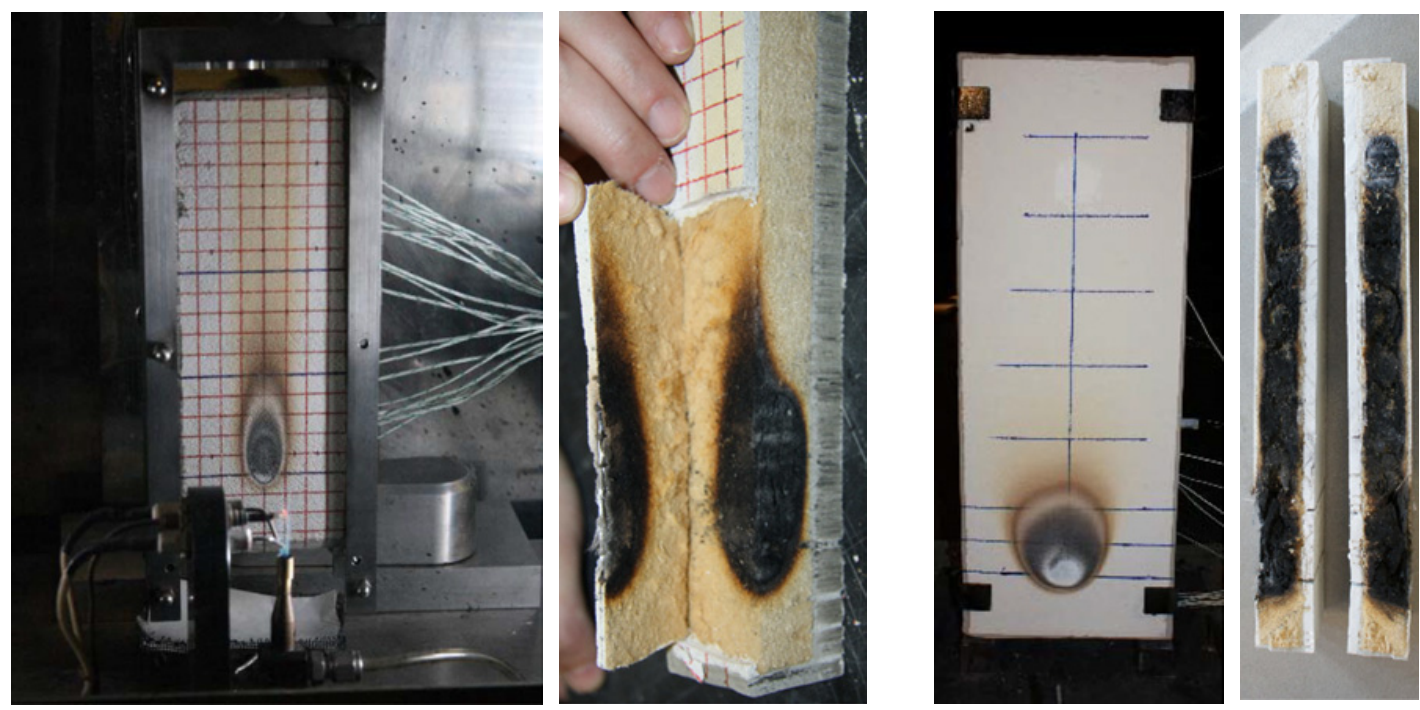

Figure 4. Plastered wood fibreboard performing the modified single-flame source test (left) [iBMB] and the smouldering test (right) [HSMD].

Currently only two samples with flame-retardants and different density are tested and analysed, so the influence cannot be estimated in detail yet. The measured temperatures indicate no decrease of the smouldering velocity. These results do not imply that the flame-retardants are not effective as they are designed for decreasing the heat release rate as well as flame spread. This complies with the observed smaller initial areas (black/decomposed area) of equipped boards (Fig. 2) and the delayed temperature increase measured at the lowest thermocouples (TC 1 and 2). Another general observation was that the equipped boards left more residues than the boards without flame-retardants.

First results of the analyses of board with different thickness are showing the influence of this parameter. Observing the smouldering front, after the nearly circular smouldering at the beginning until reaching the edges of the specimen, a parabolic course was determined. It is supposed, that this course, which was observed at all surfaces (front, back and sides), is caused by cooling effects at the edges. A further insight is the influence of the surrounding temperature during the test, which affects obviously the smouldering velocity.

In general, further tests are needed to provide a greater data base for a more detailed analysis. These tests shall underline the mentioned theses. Furthermore, they are planed with additional thermocouples to get more detailed information about the smouldering velocity in different directions for comparison with the abovementioned modified single-flame source tests.

One of the most important parameters for the system development is the minimum temperature of starting decomposition processes of the wood fibreboards (protected by the plaster system) in the ETICS. A first impression of this characteristic is given by the test method described in [8]: In the cone-calorimeter the temperature is measured between a gypsum board (representing a protective layer) and the samples of wood fibreboards. The method was developed for estimating protection criteria for (sustainable) combustible materials for their application as insulation in construction elements, e.g. timber panel wall systems for building-class 4, where any decomposition should be prevented. First occurrence of discoloration of the insulation material is the criteria of the method according to [8]. Because of the different application (as ETICS), it was decided for this project to accept little discoloration, but to receive mass loss and oxygen calorimetry as indication for pyrolysis. The tests were performed with temperature steps of $25^{\circ} \mathrm{C}$ and led to a critical temperature of $350^{\circ} \mathrm{C}$ for all examined 


\section{MATEC Web of Conferences}

wood fibreboards (with and without flame-retardants), except a board with high density (of ca. $190 \mathrm{~kg} / \mathrm{m}^{3}$ and a critical temperature of $375^{\circ} \mathrm{C}$ ). This will be verified by further tests (of high density boards for example). The first test results assume, that smouldering processes start, if this temperature is reached behind the plaster while a fire exposure to an ETICS. Therefore, this temperature can be defined as initial temperature for smouldering processes. Currently, test with plastered samples are in process to find out, if and how long respectively how far the initialized smouldering is going on in this enclosed system (see below).

DIN 4102-15/16 and prEN 16733 define the end of a smouldering process, when no temperature above $50^{\circ} \mathrm{C}$ is measured. According to the temperature-time curves shown in Fig. 3 with the inflexion point at around 80 to $110^{\circ} \mathrm{C}$, temperatures below $50^{\circ} \mathrm{C}$ seem to be a good criterion for no occurrence of smouldering. Related to the aforementioned cone-calorimeter results of 'protected' wood fibreboards, $50^{\circ} \mathrm{C}$ should be only a criterion for progression but not for initialising.

In addition to the smouldering tests analysing the wood fibreboards themselves respectively comparing them, plastered boards were investigated. For these tests, the wood fibreboards were affixed to a gypsum board and plastered with a standard plaster system at the front and a plaster at the sides to close the system. To ensure a started smouldering process, a thermocouple was installed between the plaster and the wood fibreboard at the same height where the burner is placed. The burner flame is applied until a temperature of $350^{\circ} \mathrm{C}$ is measured here. During the following observation time, further thermocouples measure the smouldering process.

Figure 4 is showing wood fibreboards, plastered with a thin layer system of ca. $6 \mathrm{~mm}$, performing the smouldering test according prEN 16733 after the fire exposure of ca. $12 \mathrm{~min}$ until $350^{\circ} \mathrm{C}$ were reached behind the plaster. During the modified single-flame source test, a fire exposure of almost 25 min was necessary to reach the "initial temperature" of $350^{\circ} \mathrm{C}$. No visible cracks arose and the smouldering process seemed to be stopped ca. $60 \mathrm{~min}$ after the fire exposure. The plaster system could not prevent a decomposition of the wood fibreboard in the initial area, but it seemed to stop the smouldering process, probably by reducing the oxygen entry into the system sample. This result underlines the relevance of the plaster system as a protection measure. In contrast, the fire exposure in the smouldering test device arises cracks in the plaster in the initial area, a "real" smouldering process started and lasted around $55 \mathrm{~h}$. As next step, a smouldering test with a thick layer system $(15 \mathrm{~mm})$ is planned to find out, if this plaster system can prevent crack development for the mentioned test conditions and may stop the decomposition process earlier.

These test results are needed to analyse the complex fire behaviour of an ETICS with wood fibreboards and dimensioning protection measures. This means the improvement of wood fibreboards and the dimensioning of further protection measures e.g. the plaster system or the smouldering barriers.

\section{PLASTER SYSTEM}

Plaster and claddings are commonly used as fire protection for steel and timber constructions and there are existing classifying methods, e.g. EN 13501-2. Due to these classification tests and research results carried out at iBMB [9-11], the protection effects are known. Compared to fire protection claddings for construction elements, the plastering of ETICS is much thinner and not as effective. On the other hand, the test conditions for ETICS are different compared to construction elements. However, in this project, the maximum applicable thickness of the ETICS plaster is investigated, as well as fire protection additives for the plaster. This leads to various plaster compositions.

As first step of this part of the research project, the heat transfer through the plaster is measured in the cone-calorimeter. These tests are for orientation and comparison of samples with one another, so that a reasonable choice can be made for more expensive standard fire tests. Although the test area of cone-calorimeter samples being $10 \times 10 \mathrm{~cm}^{2}$ a size of $16 \times 16 \mathrm{~cm}^{2}$ was chosen to reduce the lateral heat transport (outside of the test area). Mineral wool was used as insulation material below the sample. 
$2^{\text {nd }}$ International Seminar for Fire Safety of Facades, Lund (Sweden), 2016

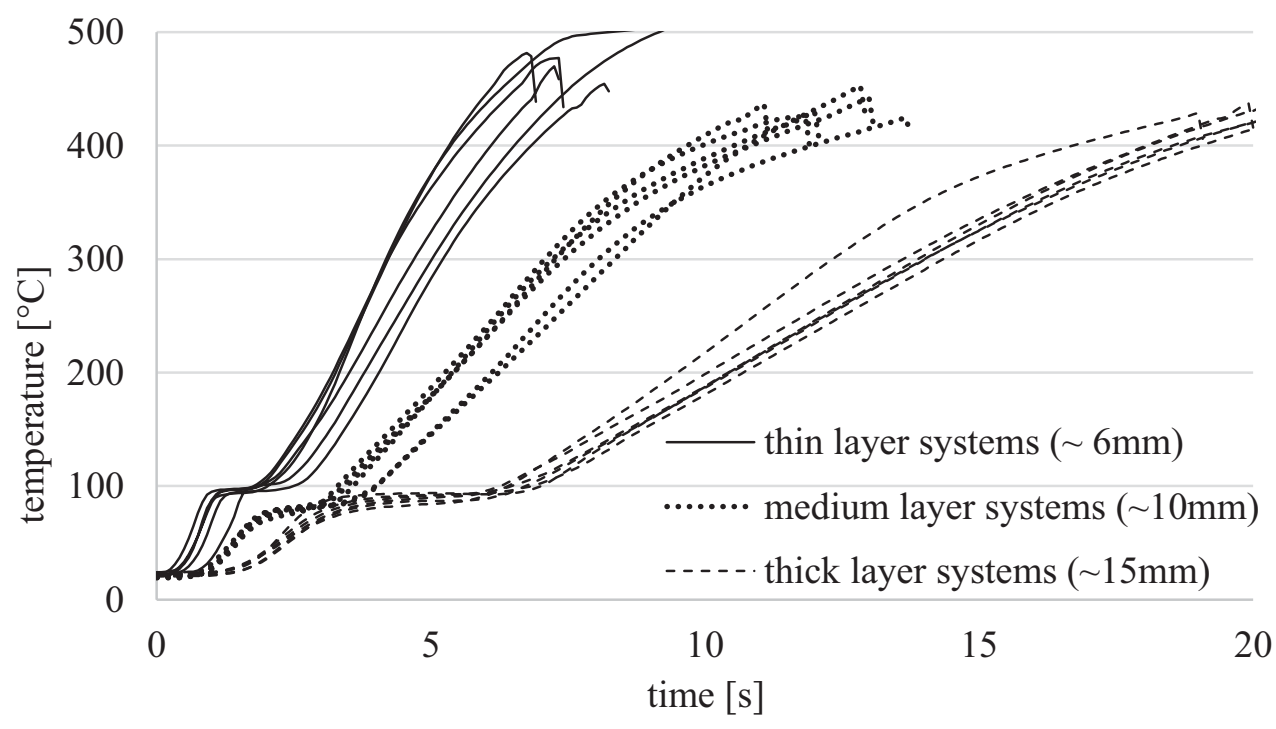

Figure 5. Heat transfer through different plaster systems measured in the cone-calorimeter [iBMB].

This noncombustible insulation was chosen instead of a combustible one because of the test objective (assessment of the heat transfer through the plaster and not the combustion of the insulation material). The heater of the cone-calorimeter produces a nearly continuous heat flux. For these investigations, the heat flux was set to $40 \mathrm{~kW} / \mathrm{m}^{2}$; this is nearly equal to the heat flux of the standard fire according to E DIN 4102-20 in a height of $1 \mathrm{~m}$ above the opening [12]. These test settings also allow a comparison with the former measurements [9-11]. In each test, five thermocouples placed between the plaster sample and the insulation measured the heat transfer. The five resulting temperature-time curves were close to each other, so that the average was chosen for comparison.

For the first test series, the project partner Endress produced plaster samples of ca. 6, 10 and $15 \mathrm{~mm}$ thickness with different composition of additives with emphasis on volumetric comparability. The measurements (Fig. 5) are underlining the results of the former project [9-11], that mostly the thickness influences the protection effects. Considering these results and having a look at the little differences, Endress produced plaster samples for the second test series, which will be tested in the cone-calorimeter again under the same conditions.

Furthermore, optimisation and application tests are in process to enlarge the maximum applicable thickness in a cooperation between Endress as plaster producer and Homatherm as wood fibreboard producer. Because of the limited plaster thickness, it is possible that the described measures will not prevent or stop the smouldering processes as required. Therefore smouldering protection barriers shall be developed.

\section{FURTHER PROTECTION MEASURES}

As further measures, smouldering protection barriers are conceivable. These barriers shall stop the smouldering process at an acceptable level, thus they have to be noncombustible. To define the placement of barriers, the fire behaviour and the smouldering velocity of the wood fibreboard have to be known as well as the expected fire exposure and the safety requirements resulting from risk analyses (see below). 

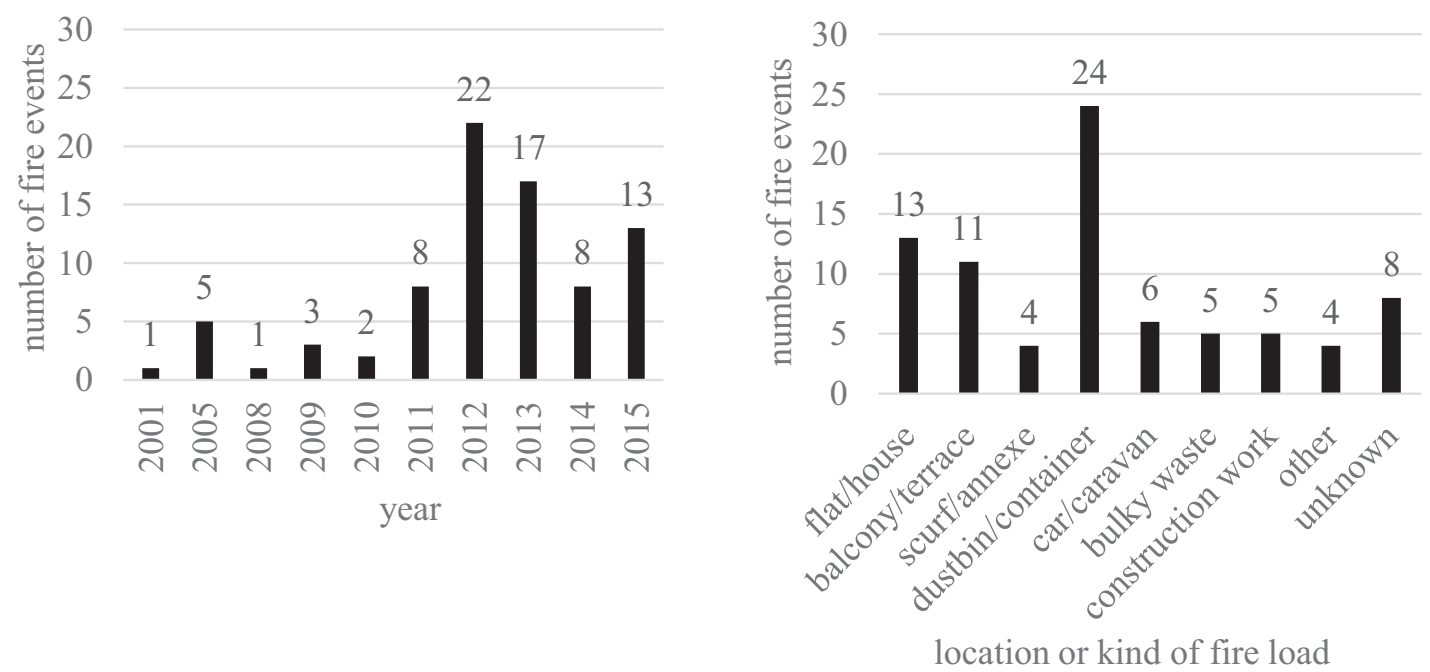

Figure 6. Occurrence and location or kind of fire load of fire events.

In addition, the requirements for thermal protection have to be considered. Currently, the material properties of different noncombustible materials are analysed with regard to their suitability as smouldering protection barrier.

\section{SAFETY AND RISK ANALYSES}

The mentioned requirements of the German model building code represent the fire safety level of exterior wall cladding, which increases with the building-class. Insulation materials of ETICS for building-class 4 and 5 have to exhibit their low flammability. One of the wood fibreboards of the project partner Homatherm is classified as euroclass C, but does not comply with the German smouldering criteria. Due to this, the use of ETICS with wood fibreboards is prohibited in the building-classes 4 and 5 .

In Germany for application of an ETICS for building-class 4 and 5 the insulation materials do not only have to pass the standard fire test (reaction for fire), the whole system has to perform an additional (nearly) real-scale test (according to E DIN 4102-20). This is reasoned by the practical application as an ETICS consisting of different components.

Currently, several facade fire events arose a controversial discussion about fire safety of facades. One reaction was a research project commissioned by the building ministers. Within this project some tests with a fire load (wood crib) of ca. $2 \mathrm{MW}$, placed at the ground in front of an ETICS with EPS (socle fire scenario), were carried out [13, 14]. Before this, the window fire scenario of E DIN 4102-20 was expected as covering the socle fire scenario $[15,16]$. The mentioned fire tests resulted in an instructtion paper [17] requiring more fire protection barriers in EPS systems.

The fire brigade of Frankfurt (Main) collects ETICS fire events with EPS in Germany [18]. Due to a standardised questionnaire on their homepage, the fire events can be reported. The current list (status august 2015) was analysed in dependence to [13].

Analysing this data it has to be considered that the reports are carried out on a voluntary basis. There is no commitment of reporting facade fire events and no standard fire statistic in Germany. Due to this, it is intended to generate an additional database in this research project. The fire brigade of Braunschweig tested first versions of a modified questionnaire developed by the iBMB. Currently, other fire brigades shall be convinced for supporting this investigation by participation. The cooperation with 
different fire brigades shall be the basis for a nationwide extrapolation and the estimation of the relevant risk parameters, e.g. criteria for an acceptable fire behaviour.

In addition to this kind of damage and risk analyse, wood fibreboard unions and organisations as well as a central insurance organisation $[19,20]$ were questioned about fire events with wood fibreboard ETICS. The only reply was a fire damage during the building process of a wood fibreboard ETICS in 2010. This complies with the mentioned fire events with wood fibreboards in [20], where no facade fire is listed. The author approved that the damage report still represents the current situation [19].

As main reason for the little number of registered fire events with wood fibreboard ETICS, the little distribution of such ETICS is assumed. That is why the damage analyses in this project cannot focus on fire damages at wood fibreboard ETICS. In addition to the mentioned damage analyses and statistic, theoretical and numerical analyses are in process, e.g. [13].

The results of the safety and risk analyses as well as the research and development results will be discussed with representatives of the building authority, insurance organisations, fire brigades and industry. A successive integration of these partners in the developing process shall lead to an objectiveand performance-based design.

\section{CONCLUSION AND OUTLOOK}

This paper presents first results of standardised and innovative investigation methods as basis for the development of an ETICS with wood fibreboards for multi-storey buildings. The current research work focuses on the smouldering behaviour of wood fibreboards as the main reason why they do not comply with the requirements for application in building-class 4 and 5 . The results imply that a value of $350^{\circ} \mathrm{C}$ as initialising temperature of smouldering processes is valid for most of the investigated wood fibreboards and temperatures lower than $50^{\circ} \mathrm{C}$ could be confirmed as criteria for a stopped or decreasing smouldering process. Although the first test results could not identify a decrease of the smouldering velocity when flame-retardants are used, a smaller initial area and delayed temperature increase in or close to the initial area was measured. These and other influencing parameters are studied in ongoing tests in more detail. In addition to these investigations, safety and risk analyses are needed for dimensioning protection measures.

The plaster system, for example, serves as protection measure. Plaster samples with different additive compositions are studied in the cone-calorimeter. The first results underline the results of the former project [9-11]: The plaster thickness influences mainly the performance criteria for fire protection. Additional compositions will be examined in the cone-calorimeter and the maximum applicable plaster thickness is investigated in a cooperation between the involved plaster and wood fibreboard producers. Other constructive measures, e.g. smouldering protection barriers, are also considered and will be investigated.

In addition to the mentioned investigations of smouldering, risk and safety analyses are needed for defining the performance criteria of these measures and dimensioning the system for application. All components have to be arranged according to their performance. At first, small single specimen will be investigated and then, the assembled components will be tested under more realistically conditions. At the end of the project, the newly developed system has to perform a large-scale fire test.

The research project was funded within the Central Innovation Program for Small- and Medium-sized Enterprises (ZIM) of the German Federal Ministry of Economics and Technology, for which the authors are grateful. Furthermore, thanks to the involved partners: Fraunhofer Institute for Wood Research (WKI), fire brigade of Braunschweig, Wolfgang Endress Kalk- und Schotterwerk GmbH \& Co. KG, Holzbau Weizenegger GmbH, HOMATHERM GmbH and the further industrial partners GUTEX Holzfaserplattenwerk H. Henselmann GmbH \& CO. KG, STEICO SE and UNGER-DIFFUTHERM GmbH. 


\section{References}

[1] Ohlmiller, T. J., "Smouldering Combustion". In SFPE Handbook of Fire Protection Engineering (P. J. DiNenno, Ed.), Springer, Westford, 2002.

[2] Rein, G., "Smouldering Combustion". In SFPE Handbook of Fire Protection Engineering (M. J. Hurley, Ed.) Springer, New York, 2016.

[3] Hölemann, H., "Schwel- und Glimmversuche an Baustoffen”, wksb, 18/1984, 1-9, 1984.

[4] Hölemann, H., "Entwicklung eines Prüfverfahrens für die Bewertung von schwel- und glimmfähigen Baustoffen”, vfdb-Zeitschrift, 1/97, 11-19, 1997.

[5] Hölemann, H., "Schwelbrände - Abgrenzung, Entstehung, Ausbreitung, Brandbekämpfung", vfdb-Zeitschrift, 3/2009, 124-132, 2009.

[6] Gertlová, Z., Bergmeister, K., Marková, I., Cunderlík, I., Wegener, G., and Windeisen, E., "Schwel- und Glimmverhalten von Dämmstoffen", Institut für Konstruktiven Ingenieurbau, Universität für Bodenkultur Wien, Veröffentlichung des Institutes, Heft Nr. 49, Wien, Österreich, 2001, ISSN 1028-5334, ISBN 3-900962-27-8.

[7] Adamietz, P., Ehrlenspiel, R., Richter, K., "Experimental Study on Smoldering Combustion of Construction Products", Proceedings of Fire and Materials, 297-308, San Francisco, USA 28-30 January, 2013.

[8] Kampmeier, B., "Risikogerechte Brandschutzlösungen für den mehrgeschossigen Holzbau", Dissertation, Braunschweig, Germany, 2008.

[9] Wachtling, J., Hosser, D., Zehfuß, J., "Fire protection of multi-storey straw bale buildings", Proceedings of Research and applications in Structural Engineering, Mechanics and Computation, (A. Zingoni, Ed.), 707-708, Cape Town, 2-4 September, 2013, ISBN 978-1-138-00061-2.

[10] Hosser, D., Zehfuß, J., Wachtling, J., "Direktverputzte Strohballenbauteile für die Gebäudeklasse 4 - Teilprojekt Brandschutztechnische Untersuchungen”, Abschlussbericht ZIMFörderkennzeichen: KF 2178804 KI0, 2014.

[11] Küppers, J., Hosser, D., Zehfuß, J., "Neue Forschungsergebnisse zum Brandschutz für mehrgeschossige Strohballenbauten”, vfdb-Zeitschrift, 1/2015, 20-27, 2015.

[12] White, N., Delichatsios, M., "Fire Hazards of Exterior Wall Assemblies Containing Combustible Components", Final Report, Fire Protection Research Foundation, Quincy, Massachusetts, USA, 2014.

[13] Kaudelka, S., Hofmann-Böllinghaus, A., Hauswaldt, S., Krause, U., "Auswirkungen von Zündquellen und Systembeschaffenheit auf das Brandverhalten EPS-basierter WärmedämmVerbundsysteme", Bauphysik, 37, 205-212, 2015, (http://onlinelibrary.wiley.com/doi/ 10.1002/bapi.201510023/epdf).

[14] Zehfuß, J., Riese, O., Northe, C., Küppers, J., "Experimentelle und numerische Erkenntnisse zum Brandverhalten von WDVS-Fassaden auf Polystyrol-Basis", Bauingenieur, 12-2015, 567-574, 2015.

[15] Kotthoff, I., "Wie brennt was? - Brandszenarien am Beispiel der Gebäudeaußenwand", Fachzeitschrift zuschnitt, 14, 2004, (http://www.proholz.at/zuschnitt/14/wiebrennt-was/).

[16] Hofmann-Böllinghaus, A., Kaudelka, S, "Wärmedämmverbundsysteme - Neue Erkenntnisse aus Versuchen und Analysen aktueller Brandereignisse", Proceedings of 62. Jahresfachtagung der Vereinigung zur Förderung des Deutschen Brandschutzes e. V., 291-304, Dortmund, Germany, 16-18 Juni, 2014.

[17] Hinweis des Deutschen Instituts für Bautechnik (DIBt): WDVS mit EPS-Dämmstoff, Konstruktive Ausbildungen zur Verbesserung des Brandverhaltens von als "schwerentflammbar" einzustufenden Wärmedämmverbundsystemen mit EPS, Stand 16. Dezember 2014. https://www.dibt.de/de/Fachbereiche/data/Merkblatt_Sicherstellung_der_ Schutzwirkung_von_EPS-WDVS_18062015.pdf Fankfurther Liste 
$2^{\text {nd }}$ International Seminar for Fire Safety of Facades, Lund (Sweden), 2016

[18] Homepage of the fire brigade of Frankfurt (Main) and the project reporting fires with EPS-ECTIS (http://www.feuerwehr-frankfurt.de/index.php/projekte/wdvs)

[19] Engfeld, A., "Baustoff Holzweichfaserplatten - Ein ökologischer, aber brandgefährlicher Baustoff", Schadenprisma, 1/2009, 4-8, 2009.

[20] Engfeld, A., Institut für Schadenverhütung und Schadenforschung der öffentlichen Versicherer, Interview transcript, 2 September, 2015. 